\title{
Fructose-1,6-Bisphosphate Protects Hippocampal Rat Slices from NMDA Excitotoxicity
}

\author{
Kamal M. Yakoub ${ }^{1,2,+}$, Giacomo Lazzarino ${ }^{3,4,+}$, Angela M. Amorini ${ }^{5,+}{ }^{\oplus}$, Giuseppe Caruso ${ }^{6}(\mathbb{D}$,

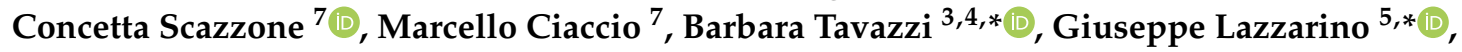 \\ Antonio Belli ${ }^{1,2}$ and Valentina Di Pietro ${ }^{1,2}$ \\ 1 Neurotrauma and Ophthalmology Research Group, School of Clinical and Experimental Medicine, \\ College of Medical and Dental Sciences, University of Birmingham, Edgbaston, Birmingham B15 2TT, UK; \\ k.yakoub@bham.ac.uk (K.M.Y.); a.belli@bham.ac.uk (A.B.); v.dipietro@bham.ac.uk (V.D.P.) \\ 2 National Institute for Health Research Surgical Reconstruction and Microbiology Research Centre, \\ Queen Elizabeth Hospital, Edgbaston, Birmingham B15 2TH, UK \\ 3 Institute of Biochemistry and Clinical Biochemistry, Catholic University of Rome, Largo F. Vito 1, \\ 00168 Rome, Italy; giacomo.lazzarino@unicatt.it \\ 4 Fondazione Policlinico Universitario A. Gemelli IRCCS, Largo A. Gemelli 8, 00168 Rome, Italy \\ 5 Department of Biomedical and Biotechnological Sciences, Division of Medical Biochemistry, University of \\ Catania, Viale A. Doria 6, 95125 Catania, Italy; amorini@unict.it \\ 6 Oasi Research Institute-IRCCS, Via Conte Ruggero 73, 94018 Troina (EN), Italy; \\ forgiuseppecaruso@gmail.com \\ 7 Institute of Clinical Biochemistry, Clinical Molecular Medicine and Laboratory Medicine, Department of \\ Biomedicine, Neurosciences and Advanced Diagnostics, Via del Vespro 129, 90127 Palermo, Italy; \\ concetta.scazzone@unipa.it (C.S.); marcello.ciaccio@unipa.it (M.C.) \\ * Correspondence: barbara.tavazzi@unicatt.it (B.T.); lazzarig@unict.it (G.L.); \\ Tel.: +39-06-30155135 (B.T.); +39-095-7384095 (G.L.) \\ + These Authors equally contributed to this work.
}

Received: 16 April 2019; Accepted: 4 May 2019; Published: 7 May 2019

Abstract: Effects of fructose 1,6-bisphosphate (F-1,6-P2) towards N-methyl-D-aspartate NMDA excitotoxicity were evaluated in rat organotypic hippocampal brain slice cultures (OHSC) challenged for $3 \mathrm{~h}$ with $30 \mu \mathrm{M}$ NMDA, followed by incubations (24, 48, and $72 \mathrm{~h}$ ) without (controls) and with F-1,6-P2 (0.5, 1 or $1.5 \mathrm{mM})$. At each time, cell necrosis was determined by measuring LDH in the medium. Energy metabolism was evaluated by measuring ATP, GTP, ADP, AMP, and ATP catabolites (nucleosides and oxypurines) in deproteinized OHSC extracts. Gene expressions of phosphofructokinase, aldolase, and glyceraldehyde-3-phosphate dehydrogenase were also measured. F-1,6-P2 dose-dependently decreased NMDA excitotoxicity, abolishing cell necrosis at the highest concentration tested $(1.5 \mathrm{mM})$. Additionally, F-1,6-P2 attenuated cell energy imbalance caused by NMDA, ameliorating the mitochondrial phosphorylating capacity (increase in ATP/ADP ratio) Metabolism normalization occurred when using $1.5 \mathrm{mM} \mathrm{F-1,6-P2.} \mathrm{Remarkable} \mathrm{increase} \mathrm{in} \mathrm{expressions}$ of phosphofructokinase, aldolase and glyceraldehyde-3-phosphate dehydrogenase (up to 25 times over the values of controls) was also observed. Since this phenomenon was recorded even in OHSC treated with F-1,6-P2 with no prior challenge with NMDA, it is highly conceivable that F-1,6-P2 can enter into intact cerebral cells producing significant benefits on energy metabolism. These effects are possibly mediated by changes occurring at the gene level, thus opening new perspectives for F-1,6-P2 application as a useful adjuvant to rescue mitochondrial metabolism of cerebral cells under stressing conditions.

Keywords: fructose-1,6-bisphosphate; $N$-methyl-D-aspartate; excitotoxicity; energy metabolism; mitochondrial dysfunction; organotypic hippocampal brain slice cultures 


\section{Introduction}

Brain damage caused by acute (ischemia, stroke, hypoxia, traumatic brain injury) and chronic neurological disorders (Alzheimer's disease, Parkinson's disease, multiple sclerosis) has some common biochemical features including ionic imbalance [1], cell energy failure [2] and increase in the release of neurotransmitters with inhibition of their reuptake [3]. This last phenomenon mainly involves glutamate, the most important excitotoxic neurotransmitter. Glutamate binds to ionotropic $N$-methyl-D-aspartate (NMDA), $\alpha$-amino-3-hydroxy-5-methyl-4-isoxazolepropionic acid (AMPA), kainic acid rceptors, as well as to metabotropic receptors, promoting a major influx of calcium into neurons and astrocytes. Re-uptake by astrocytes is crucial to terminate glutamate signaling and to prevent the insurgence of the dangerous phenomenon known as glutamate excitotoxicity [4]. Using NMDA, which acts as an agonist for NMDA receptor, it is possible to mimic glutamate excitotoxicity in various experimental conditions $[5,6]$.

Under pathological conditions, the glutamate-glutamine cycle involving neurons and astrocytes is impaired leading to glutamate excitotoxicity with massive calcium influx within mitochondria. Calcium overload initiates excitatory events involving free radical generation, triggering of apoptosis through processing caspase cleavage, opening of the mitochondrial permeability transition pore. This last event causes the depolarization of the mitochondrial inner membrane damaging the major role of mitochondria, i.e., the correct functioning of the electron transfer chain (ETC) coupled to oxidative phosphorylation (OXPHOS), and causing transient or permanent mitochondrial malfunction $[2,5]$. The consequences are a decreased efficiency in adenosine triphosphate (ATP) synthesis, with imbalance in ATP production and consumption and cell energy deficit. Therefore, decrease in the neuronal ATP levels contributes to exacerbate the imbalance in ionic homeostasis in brain cells and creates a vicious circle linking glutamate excitotoxicity, mitochondrial activity and cell energy metabolism $[7,8]$. Additionally, malfunctioning mitochondria cause increased production of reactive oxygen and nitrogen species (ROS and RNS), leading to the insurgence of oxidative/nitrosative stress [9], and release of proapoptotic factors, with consequent activation of caspases and the intrinsic apoptotic pathway [10].

Therefore, glutamate excitotoxicity has been considered since long time a strategic target for therapeutic interventions in brain insults of different etiology [11]. Despite positive results obtained in cellular and animal models targeting NMDA and AMPA receptors with different promising drugs [12,13], the subsequent clinical trials failed to improve outcome of the patients $[14,15]$ so that effective pharmacologic treatments to decrease glutamate excitotoxicity in humans are still lacking.

Fructose-1,6-bisphosphate (F-1,6-P2) is a six carbon monosaccharide, found in both prokaryotes and eukaryotes, and produced in the third reaction of glycolysis through the activity of phosphofructokinase I. In the last decades, exogenous administration of F-1,6-P2, in concentrations (1.5-10 mM) largely exceeding its intracellular concentration $(1-5 \mu \mathrm{M})[16,17]$, has been used in a variety of pathological conditions in both preclinical and clinical studies [18]. Particularly, F-1,6-P2 improved myocardial energy metabolism [19] and decreased oxidative stress in experimental models of anoxia and re-oxygenation [20], reduced post-ischemic ventricular dysfunctions [21], improved outcome after circulatory arrest in pigs [22].

Clinically, F-1,6-P2 improved hemodynamic in patients with altered ventricular functions [23] and protected myocardium during coronary bypass surgery [24]. In models of brain injury, F-1,6-P2 protected neuronal integrity after circulatory arrest in pigs [25], preserved cerebral energy metabolism after brain ischemia [26], protected hippocampal neurons by repeated febrile convulsions [27], preserved glucose metabolism and decreased oxidative stress caused by experimental sepsis [28]. It is worth recalling that in different experimental conditions of hypoxia/ischemia F-1,6-P2 administration did not show significant beneficial effects on high energy phosphate metabolism [29,30].

Organotypic slice cultures represent a valid experimental model, maintaining neuronal maturation and plasticity, useful to evaluate experimental insults and drug treatments that can be followed for various days in vitro [31]. Using this model, toxicity of the $A \beta$ oligomer 1-40, characteristic of the Alzheimer's disease, has been evaluated in mixed neuronal-glial cerebellar cultures and 
organotypic cerebellar cultures [32]. Organotypic hippocampal slice cultures (OHSC) specifically uses hippocampal slices, mainly obtained from neonatal rats, to study the biochemical, morphological and functional characteristics of both neurons and glial cells. This model is suitable to study neurotoxicity, neuroprotection, neuronal networks or tumor invasion [33], and even to effectively mimic cellular damages induced by traumatic brain injury [34].

With the aim to clarify the effects of exogenous F-1,6-P2, in this study we tested the benefits of increasing concentrations of F-1,6-P2 on NMDA excitotoxicity induced in rat OHSC by measuring release of lactate dehydrogenase (LDH) in the medium and concentrations of various metabolites related to energy metabolism (ATP, GTP, ADP, AMP, oxypurines, nucleosides, lactate). The expression of the genes encoding for 6-phosphofructo-1-kinase (PFKL), aldolase (ALDOC) and glyceraldehyde-3-phosphate dehydrogenase (GAPDH), were also considered.

\section{Results}

\subsection{NMDA Cytotoxicity and Protection by F-1,6-P2}

The cytotoxic effects of NMDA on OHSC were clearly evidenced by the time-dependent increase of LDH in the medium (Figure 1). At 24, 48 and $72 \mathrm{~h}$ after the $3 \mathrm{~h}$ challenge with $30 \mu \mathrm{M}$ NMDA, OHSC had LDH values were 4.7, 5.1 and 6.2 times higher than the values determined in the medium of control OHSC at the same time points $(p<0.001)$. The supplementation to the culture medium of NMDA-treated OHSC with $0.5,1$ or $1.5 \mathrm{mM} \mathrm{F-1,6-P2} \mathrm{provoked} \mathrm{a} \mathrm{dose-dependent} \mathrm{beneficial} \mathrm{effect,}$ as indicated by the decreased release of LDH (Figure 1). All samples receiving F-1,6-P2 in the recovery phase, for 24, 48 and $72 \mathrm{~h}$ post challenge with $30 \mu \mathrm{M}$ NMDA, showed lower LDH values in the medium at any time point, when compared to the corresponding times of OHSC with no supplementation $(p<0.001)$. It is worth noting that $1.5 \mathrm{mM} \mathrm{F-1,6-P2} \mathrm{completely} \mathrm{abolished} \mathrm{the} \mathrm{cytotoxic} \mathrm{effects} \mathrm{of} \mathrm{NMDA,}$ so that $\mathrm{LDH}$ values in the medium of these cultures were not significantly different from those found in controls at the corresponding time points (Figure 1).

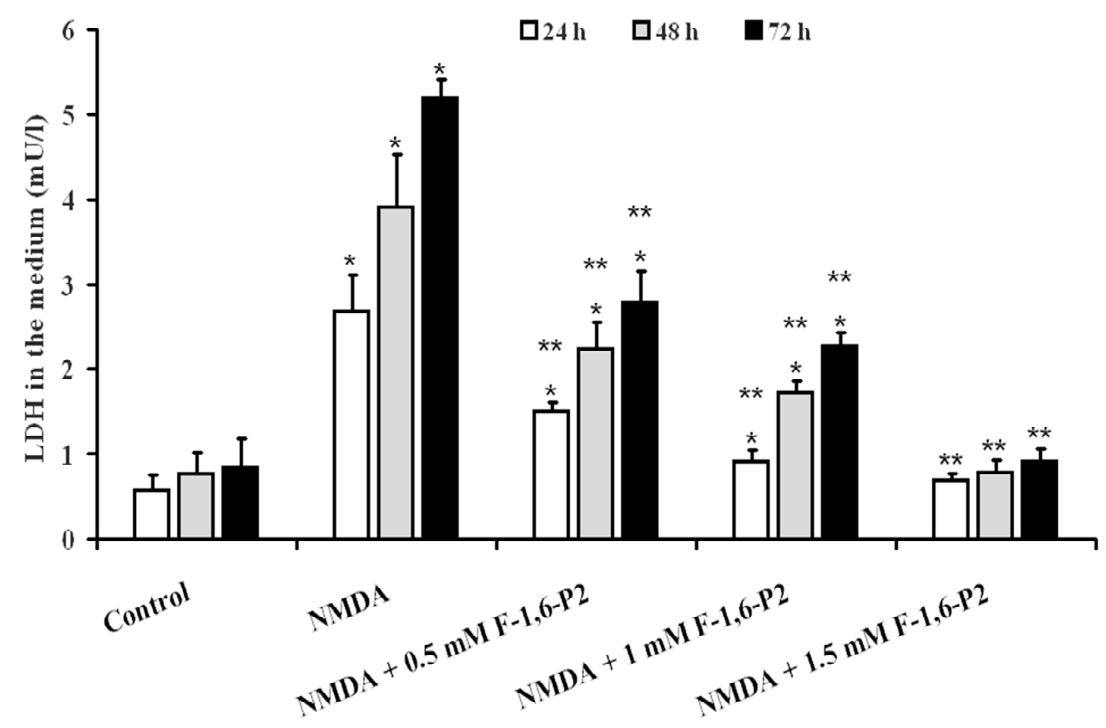

Figure 1. Protective effects of F-1,6-P2 on cell necrosis in NMDA-treated OHSC. OHSC were challenged with $30 \mu \mathrm{M}$ NMDA for $3 \mathrm{~h}$ and then incubated without and with increasing concentrations of F-1,6-P2 $(0.5,1$ and $1.5 \mathrm{mM})$ for different times $(24,48$ and $72 \mathrm{~h})$. Control OHSC were incubated for the same time intervals, with no prior NMDA treatment or F-1,6-P2 addition. Cell necrosis was deducted by the amount of $\mathrm{LDH}$ released in the culture medium and expressed as $\mathrm{mU}$ of enzyme activity/L of medium ( $1 \mathrm{U}=1 \mu \mathrm{mol} / \mathrm{min}$ of substrate consumed). Histograms are the mean of 6 different OHSC preparations. Standard deviations are represented by vertical bars. * Significantly different from corresponding time of control OHSC, $p<0.001$. ${ }^{*}$ Significantly different from corresponding time of NMDA-challenged OHSC with no F-1,6-P2 supplementation, $p<0.001$. 


\subsection{NMDA-Induced Imbalance of OHSC Energy Metabolism and Protection by F-1,6-P2}

Prolonged recovery following incubation of OHSC with $30 \mu \mathrm{M}$ NMDA for $3 \mathrm{~h}$ caused a time-dependent decline in the cell energy state. As shown in Figure 2, ATP (panel A) and GTP (panel B) concentrations in NMDA-pretreated OHSC at 24, 48 and $72 \mathrm{~h}$ incubation were $15 \%, 31 \%$ and $46 \%$, and $37 \%, 32 \%$ and $39 \%$ lower, respectively, than corresponding values detected in controls $(p<0.001)$. The addition during the recovery phase of increasing concentrations of F-1,6-P2 $(0.5$, 1 or $1.5 \mathrm{mM}$ ), to the medium of $30 \mu \mathrm{M}$ NMDA-pretreated OHSC, significantly protected cell energy metabolism. Levels of both high energy phosphates (ATP and GTP) in OHSC receiving F-1,6-P2 were significantly higher than the values recorded in OHSC with no supplement during recovery. It is particularly relevant that the beneficial effects produced by the presence of $1.5 \mathrm{mM} \mathrm{F}-1,6-\mathrm{P} 2$, during recovery of OHSC after challenging with $30 \mu \mathrm{M}$ NMDA, were capable to allow measuring values of ATP and GTP that were not different from those found in control OHSC.

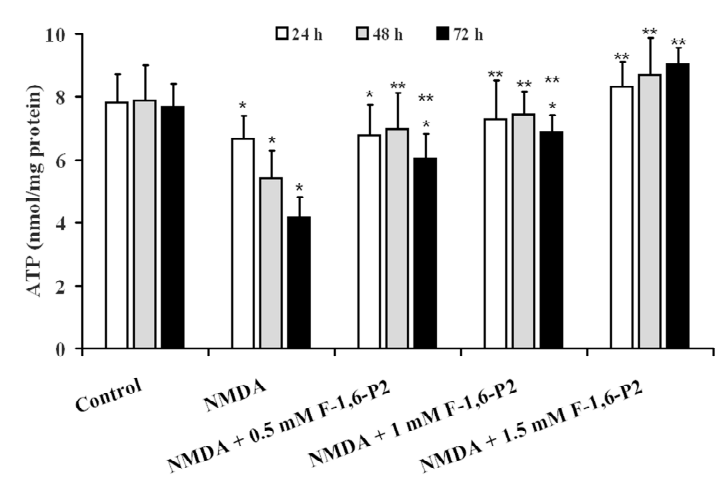

(a)

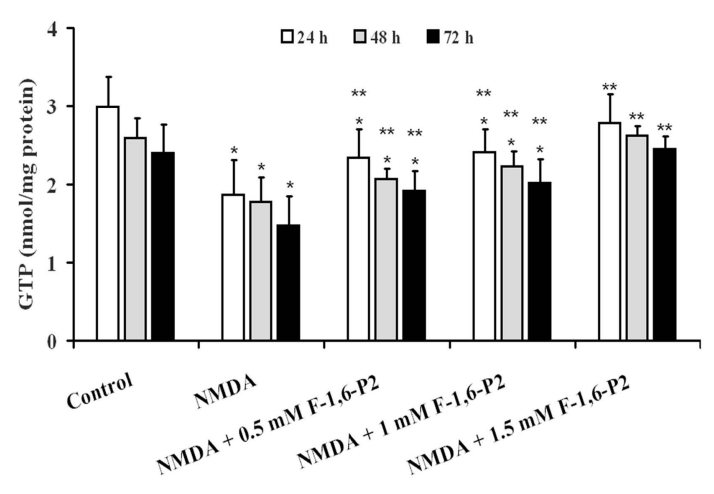

(b)

Figure 2. Effects of F-1,6-P2 on the recovery of high energy phosphate concentrations in NMDA-treated OHSC. OHSC were challenged with $30 \mu \mathrm{M}$ NMDA for $3 \mathrm{~h}$ and then incubated without and with increasing concentrations of F-1,6-P2 $(0.5,1$ and $1.5 \mathrm{mM})$ for different times $(24,48$ and $72 \mathrm{~h})$. Control OHSC were incubated for the same time intervals, with no prior NMDA treatment or F-1,6-P2 addition. ATP (a) and GTP (b) were determined by HPLC in deproteinized cell extracts. Histograms are the mean of 6 different OHSC preparations. Standard deviations are represented by vertical bars. * Significantly different from corresponding time of control OHSC, $p<0.001$. ** Significantly different from corresponding time of NMDA-challenged OHSC with no F-1,6-P2 supplementation, $p<0.001$.

The consequence of OHSC energy metabolism imbalance, caused by $30 \mu \mathrm{M}$ NMDA, was particularly evident when considering variations of AMP during the recovery phase, rather than when observing ADP changes (Figure 3 ). At 24,48 and $72 \mathrm{~h}$ post NMDA challenge, ADP and AMP were 1.2, 1.2 and 1.5, and 2.5, 3.5 and 3.8 times higher than the values determined at corresponding times in control OHSC $(p<0.001)$. Addition of 1 and $1.5 \mathrm{mM} \mathrm{F-1,6-P2} \mathrm{completely} \mathrm{abolished} \mathrm{the} \mathrm{negative}$ effect on ADP concentrations caused by pre-treatment with $30 \mu \mathrm{M}$ NMDA $(p<0.001$ compared to corresponding times of OHSC pretreated with NMDA; not significant compared to corresponding times of control OHSC). F-1,6-P2 was less effective in normalizing AMP concentrations. Even at the highest dose tested $(1.5 \mathrm{mM})$, AMP in OHSC (pretreated with $30 \mu \mathrm{M}$ NMDA) receiving F-1,6-P2 during recovery was significantly lower than values found at corresponding times in OHSC (pretreated with $30 \mu \mathrm{M}$ NMDA) with no addition during recovery $(p<0.001)$, but also significantly higher than concentrations measured in control OHSC $(p<0.001)$. 


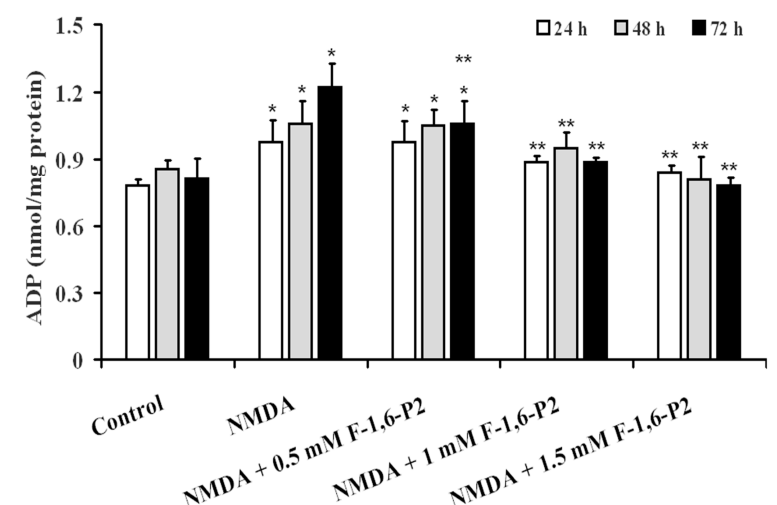

(a)

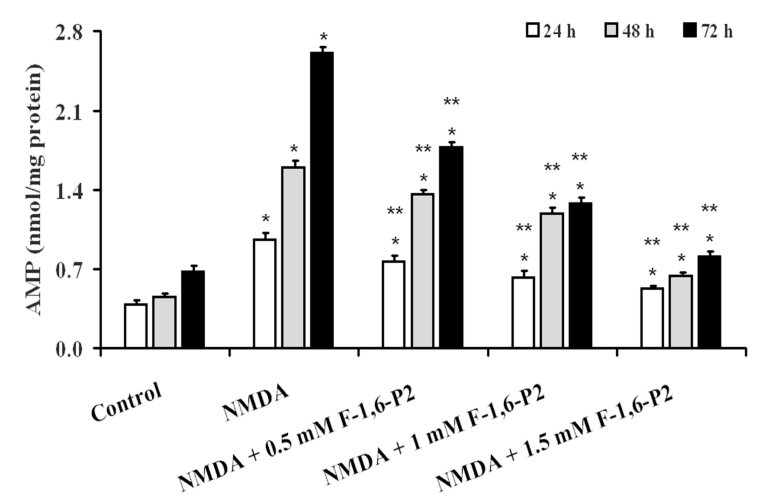

(b)

Figure 3. Effects of F-1,6-P2 on the imbalance of adenine nucleotide metabolism in NMDA-treated OHSC. OHSC were challenged with $30 \mu \mathrm{M}$ NMDA for $3 \mathrm{~h}$ and then incubated without and with increasing concentrations of F-1,6-P2 (0.5, 1 and $1.5 \mathrm{mM})$ for different times (24, 48 and $72 \mathrm{~h})$. Control OHSC were incubated for the same time intervals, with no prior NMDA treatment or F-1,6-P2 addition. ADP (a) and AMP (b) were determined by HPLC in deproteinized cell extracts. Histograms are the mean of 6 different OHSC preparations. Standard deviations are represented by vertical bars. * Significantly different from corresponding time of control OHSC, $p<0.001$. ${ }^{* *}$ Significantly different from corresponding time of NMDA-challenged OHSC with no F-1,6-P2 supplementation, $p<0.001$.

Data illustrated in Figure 4 indicate that using two indexes representing mitochondrial phosphorylating capacity (ATP/ADP ratio (Figure 4a) and cell energy wellness (ECP $=$ energy charge potential $=(\mathrm{ATP}+1 / 2 \mathrm{ADP}) /(\mathrm{ATP}+\mathrm{ADP}+\mathrm{AMP})($ Figure $4 \mathrm{~b})$, it was possible to evidence that $3 \mathrm{~h}$ incubation with $30 \mu \mathrm{M}$ NMDA caused long lasting negative effects on energy metabolism of OHSC cultures, that progressed by prolonging the time of recovery $(24,48$ and $72 \mathrm{~h}$ ). Dose-dependent ability to ameliorate both parameters was observed when supplementing $30 \mu \mathrm{M}$ NMDA-pretreated OHSC with F-1,6-P2 0.5, 1 and 1.5 mM. At the highest dose tested $(1.5 \mathrm{mM})$, OHSC receiving F-1,6-P2 had values of the ATP/ADP ratio and ECP not different from those calculated in control OHSC.

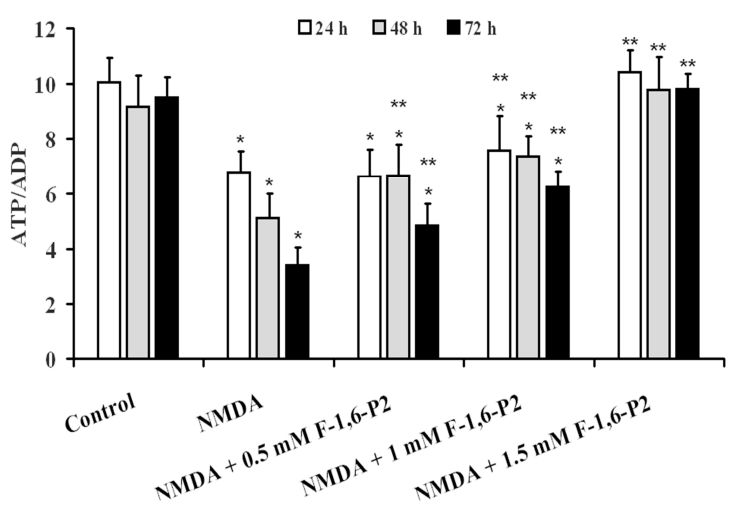

(a)

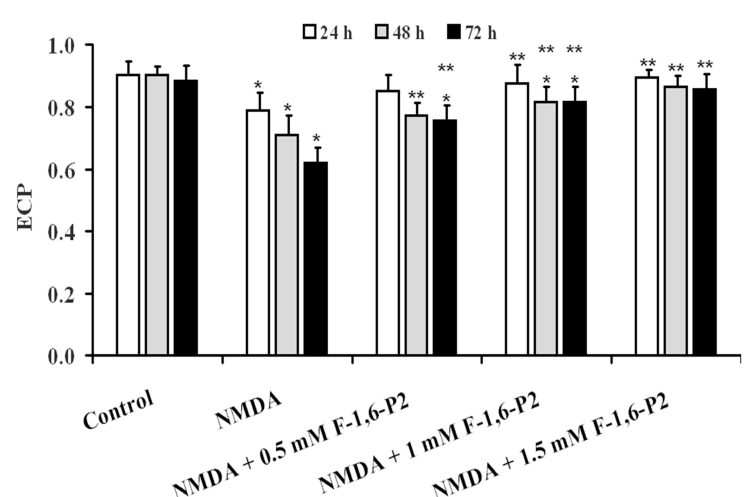

(b)

Figure 4. Effects of F-1,6-P2 on energy metabolism derangement in NMDA-treated OHSC. OHSC were challenged with $30 \mu \mathrm{M}$ NMDA for $3 \mathrm{~h}$ and then incubated without and with increasing concentrations of F-1,6-P2 (0.5, 1 and $1.5 \mathrm{mM})$ for different times $(24,48$ and $72 \mathrm{~h})$. Control OHSC were incubated for the same time intervals, with no prior NMDA treatment or F-1,6-P2 addition. ATP/ADP ratio (a) reflects the phosphorylating capacity of mitochondria. ECP $(\mathbf{b})$ indicates the cell energy wellness, according to the equation: $\mathrm{ECP}=\mathrm{ATP}+1 / 2 \mathrm{ADP} /(\mathrm{ATP}+\mathrm{ADP}+\mathrm{AMP})$. Histograms are the mean of 6 different OHSC preparations. Standard deviations are represented by vertical bars. ${ }^{*}$ Significantly different from corresponding time of control OHSC, $p<0.001$. ${ }^{*}$ Significantly different from corresponding time of NMDA-challenged OHSC with no F-1,6-P2 supplementation, $p<0.001$. 
2.3. Effects of F-1,6-P2 on Adenine Nucleotide Catabolism and Lactate Production in OHSC Challenged with NMDA

Quantification in the culture medium of products generating from ATP dephosphorylation (adenosine, inosine, hypoxanthine, xanthine and uric acid), evidenced the activation of the degradation pathway of adenine nucleotide catabolism in OHSC pretreated with $30 \mu \mathrm{M}$ NMDA and then allowed to recover for 24, 48 and $72 \mathrm{~h}$ (Figure 5). Both sum of nucleosides (Figure $5 \mathrm{a}$ ) and sum of oxypurines (Figure $5 b)$ progressively increased during the time of recovery $(p<0.001$ compared to corresponding times of control OHSC), with sum of oxypurines showing the most dramatic increases in the medium $(5.8,4.2$ and 4.8 times at 24,48 and $72 \mathrm{~h}$, respectively; $p<0.001)$.

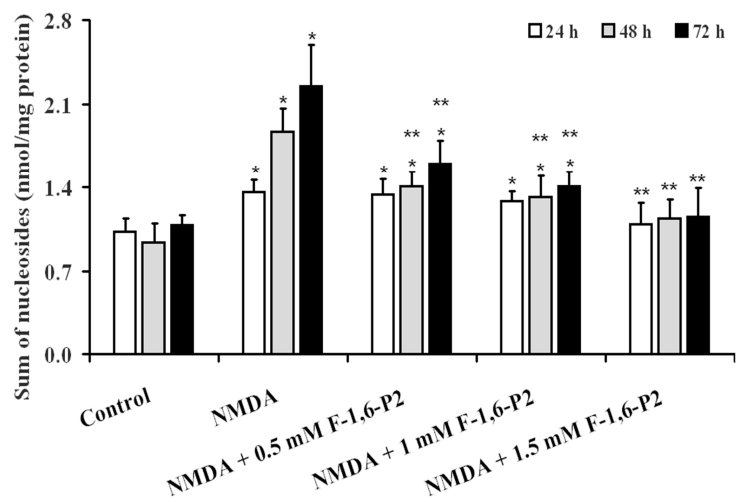

(a)

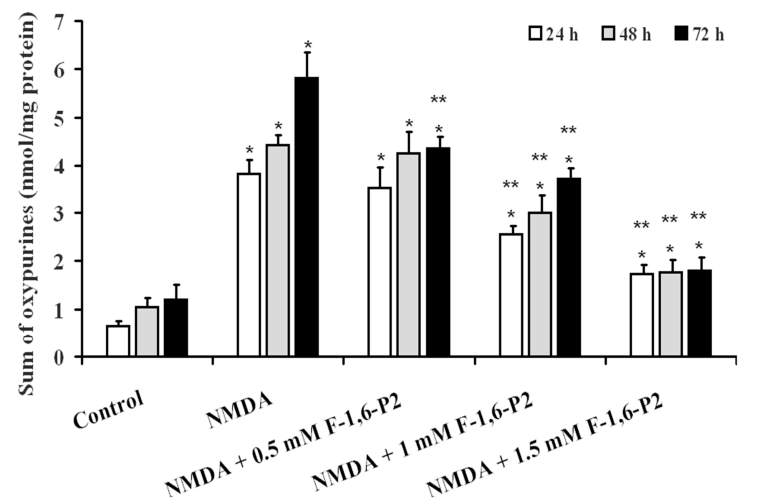

(b)

Figure 5. Effects of F-1,6-P2 on the imbalance of adenine nucleotide catabolism in NMDA-treated OHSC. OHSC were challenged with $30 \mu \mathrm{M}$ NMDA for $3 \mathrm{~h}$ and then incubated without and with increasing concentrations of F-1,6-P2 (0.5, 1 and $1.5 \mathrm{mM})$ for different times $(24,48$ and $72 \mathrm{~h})$. Control OHSC were incubated for the same time intervals, with no prior NMDA treatment or F-1,6-P2 addition. Sum of nucleosides $(\mathbf{a})=$ adenosine + inosine + guanosine. Sum of oxypurines $(\mathbf{b})=$ hypoxanthine + xanthine + uric acid. Nucleosides and oxypurines were determined by HPLC in deproteinized cell extracts. Histograms are the mean of 6 different OHSC preparations. Standard deviations are represented by vertical bars. * Significantly different from corresponding time of control OHSC, $p<0.001$. ${ }^{*}$ Significantly different from corresponding time of NMDA-challenged OHSC with no F-1,6-P2 supplementation, $p<0.001$.

The release of lactate in the medium of OHSC after challenge with $30 \mu \mathrm{M}$ NMDA (Figure 6) increased by 2.5, 3.9 and 3.8 times, respectively, at 24,48 and $72 \mathrm{~h}$, compared to values measured at corresponding times in control OHSC $(p<0.001)$. Significantly lower values were found at any time point when F-1,6-P2, at any dose tested, was added to the medium of OHSC during the recovery phase $(p<0.001)$. However, at 48 and $72 \mathrm{~h}$ after NMDA challenge, cultures supplemented with F-1,6-P2 had lactate release in the medium higher than that measured in control OHSC $(p<0.001)$. 


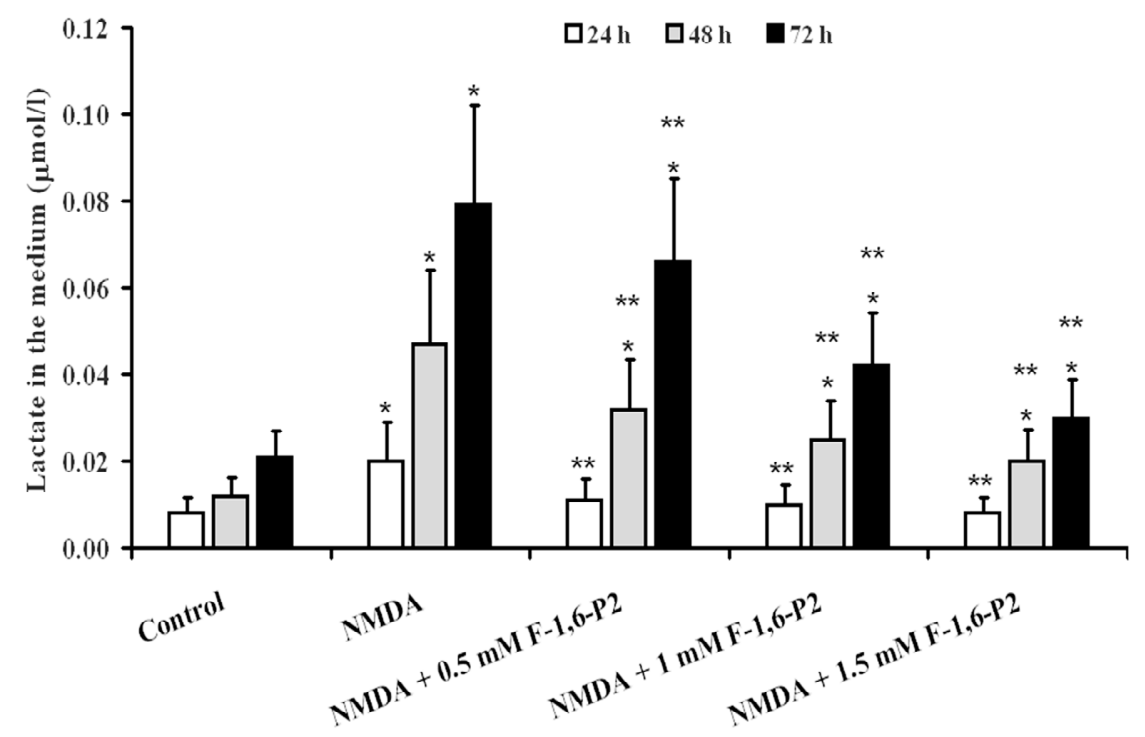

Figure 6. Effects of F-1,6-P2 on lactate production in NMDA-treated OHSC. OHSC were challenged with $30 \mu \mathrm{M}$ NMDA for $3 \mathrm{~h}$ and then incubated without and with increasing concentrations of F-1,6-P2 $(0.5,1$ and $1.5 \mathrm{mM})$ for different times $(24,48$ and $72 \mathrm{~h})$. Control OHSC were incubated for the same time intervals, with no prior NMDA treatment or F-1,6-P2 addition. Lactate was measured enzymatically in deproteinized cell extracts. * Significantly different from corresponding time of control OHSC, $p<0.001$. ${ }^{*}$ Significantly different from corresponding time of NMDA-challenged OHSC with no F-1,6-P2 supplementation, $p<0.001$.

\subsection{Expression of Genes Regulating the Synthesis of Glycolytic Enzymes Involved in F-1,6-P2 Metabolism}

Under all experimental conditions, we determined the expression of genes controlling the synthesis of the isoform L of 6-phospho-1-fructokinase (PFKL), aldolase (brain gene = ALDOC) and glyceraldehyde-3-phospate dehydrogenase (GAPDH). These three enzymes are sequentially positioned along the glycolytic pathway providing to the synthesis of F-1,6-P2 from fructose-6-phosphate and ATP (PFKL), to its hydrolysis into glyceraldehyde-3-phospate and dihydroxyacetone-3-phosphate (aldolase) and to the oxidation and phosphorylation of glyceraldehyde-3-phospate into glycerate-1,3-bisphosphate (GAPDH).

Neither control OHSC nor OHSC pretreated with $30 \mu \mathrm{M}$ NMDA and incubated for 24, 48 and $72 \mathrm{~h}$ of recovery showed any difference in the gene expression of PFKL, at any time point (Figure 7).

When $0.5 \mathrm{mM}$ F-1,6-P2 was added to the medium after challenge with $30 \mu \mathrm{M}$ NMDA, PFKL expression at 24, 48 and $72 \mathrm{~h}$ increased by 6,10 and 14 times, respectively, over the values of control OHSC at corresponding time points ( $p<0.001)$. Using $1 \mathrm{mM} \mathrm{F-1,6-P2} \mathrm{this} \mathrm{increase} \mathrm{was} \mathrm{7,} 14$ and 19 times at 24,48 and $72 \mathrm{~h}$, respectively ( $p<0.001$ compared to control OHSC). At the highest dose of F-1,6-P2 tested (1.5 mM), expression of PFKL at the same time points was 17, 20 and 27 times higher than the values recorded in control OHSC $(p<0.001)$.

Differently, 0.5 and $1 \mathrm{mM} \mathrm{F-1,6-P2} \mathrm{significantly} \mathrm{affected} \mathrm{ALDOC} \mathrm{expression,} \mathrm{after} \mathrm{challenge} \mathrm{with}$ NMDA (Figure 8a), only after $72 \mathrm{~h}$. Using these two dosages, expression of ALDOC increased by 5 and 7 times over the value measured in control OHSC $(p<0.001)$. When $1.5 \mathrm{mM} \mathrm{F-1,6-P2}$ was added to the medium during the recovery phase, ALDOC increased 1.7 and 8 times at 48 and $72 \mathrm{~h}$, respectively, in comparison with values recorded at corresponding times in control OHSC $(p<0.001)$. Similarly, 0.5 and $1 \mathrm{mM} \mathrm{F-1,6-P2}$ produced 13 and 16 times increase, respectively, in GAPDH expression only after $72 \mathrm{~h}$ of recovery post challenge with NMDA ( $p<0.001$ compared to the same time of control OHSC) (Figure 8b). Again, the effect on this gene expression of NMDA pretreated OHSC supplemented with $1.5 \mathrm{mM}$ F-1,6-P2 was significant either at 48 or at $72 \mathrm{~h}$ when 2 and 23 times higher values than those of control OHSC were recorded $(p<0.001)$. 


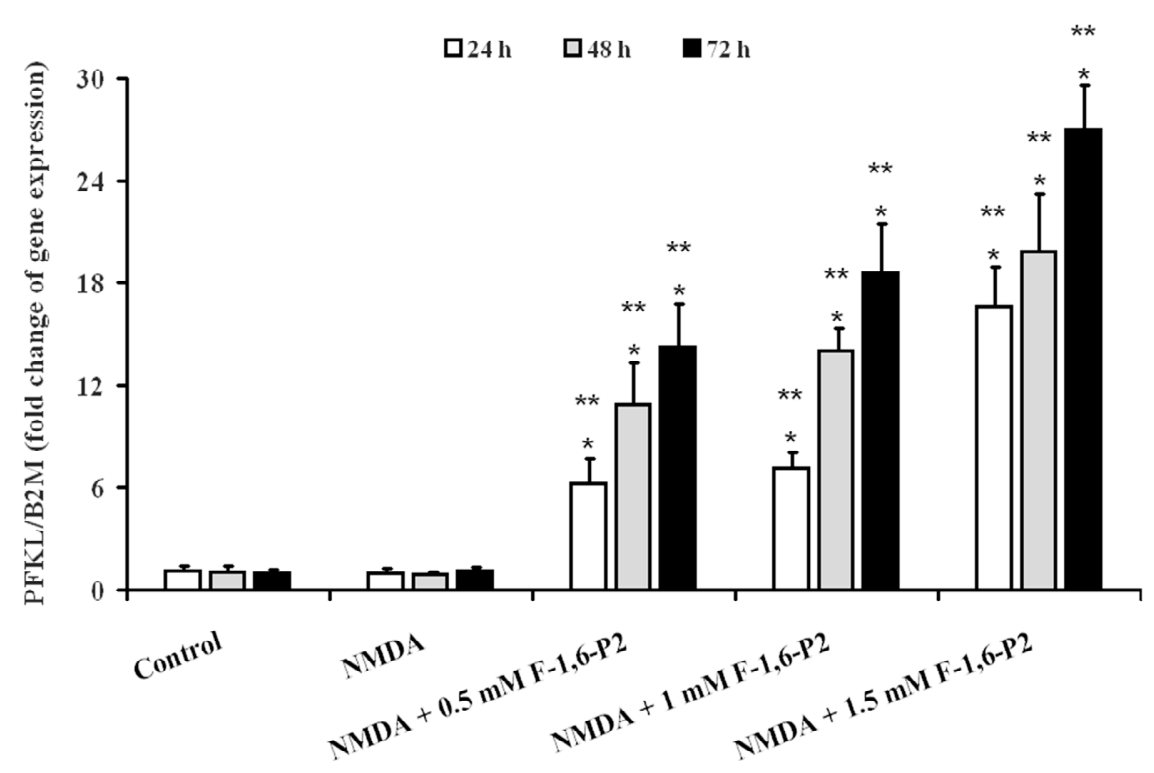

Figure 7. Effects of F-1,6-P2 on gene expression of 6-phospho-1-fructokinase (PFKL) in NMDA-treated OHSC. OHSC were challenged with $30 \mu \mathrm{M}$ NMDA for $3 \mathrm{~h}$ and then incubated without and with increasing concentrations of F-1,6-P2 $(0.5,1$ and $1.5 \mathrm{mM})$ for different times $(24,48$ and $72 \mathrm{~h})$. Control OHSC were incubated for the same time intervals, with no prior NMDA treatment or F-1,6-P2 addition. Semi-quantitative PFKL expression was determined in cell extracts, relatively to the housekeeping gene $\beta$-2-microglobulin (B2M). Histograms are the mean of 6 different OHSC preparations. Standard deviations are represented by vertical bars. * Significantly different from corresponding time of control OHSC, $p<0.001$. ${ }^{*}$ Significantly different from corresponding time of NMDA-challenged OHSC with no F-1,6-P2 supplementation, $p<0.001$.

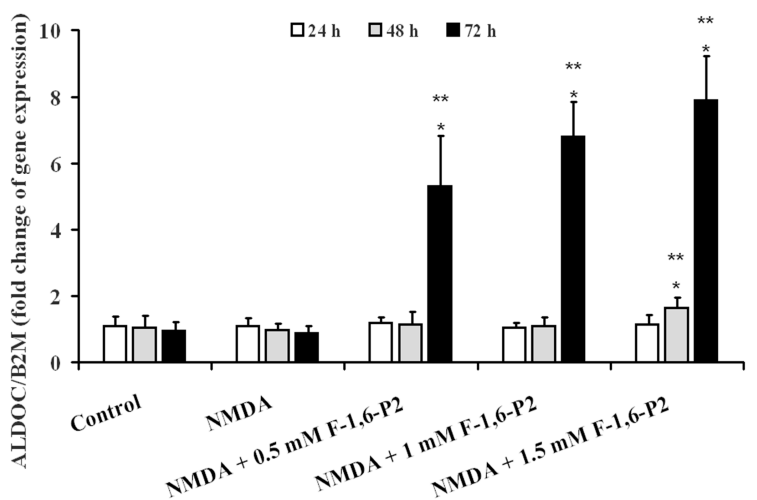

(a)

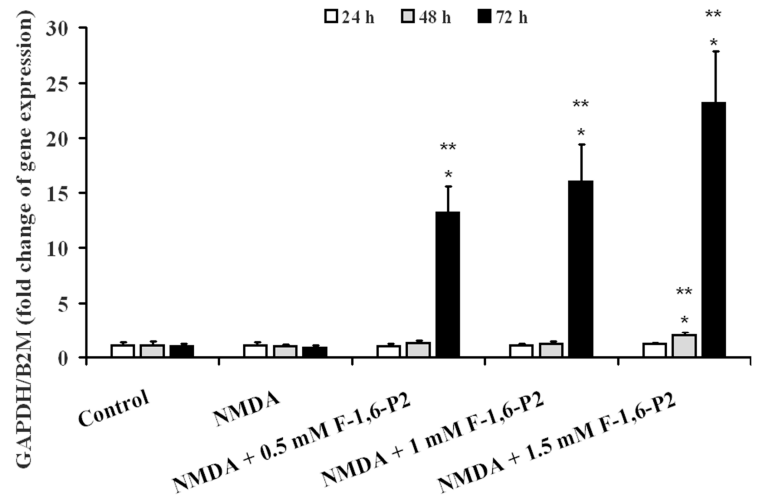

(b)

Figure 8. Effects of F-1,6-P2 on gene expression of aldolase (ALDOC) and glyceraldehyde-3-phosphate dehydrogenase (GAPDH) in NMDA-treated OHSC. OHSC were challenged with $30 \mu \mathrm{M}$ NMDA for 3 $\mathrm{h}$ and then incubated without and with increasing concentrations of F-1,6-P2 (0.5, 1 and $1.5 \mathrm{mM})$ for different times (24, 48 and $72 \mathrm{~h}$ ). Control OHSC were incubated for the same time intervals, with no prior NMDA treatment or F-1,6-P2 addition. Semi-quantitative ALDOC (a) and GAPDH (b) expressions were determined in cell extracts, relatively to the housekeeping gene $\beta$-2-microglobulin (B2M). Histograms are the mean of 6 different OHSC preparations. Standard deviations are represented by vertical bars. * Significantly different from corresponding time of control OHSC, $p<0.001$. ** Significantly different from corresponding time of NMDA-challenged OHSC with no F-1,6-P2 supplementation, $p<0.001$.

In a different set of experiments, we evaluated the effects of the addition of increasing concentrations of F-1,6-P2 on the gene expressions of PFKL, ALDOC and GAPDH of OHSC with no previous challenge with NMDA. Data summarized in Table 1 showed that F-1,6-P2 caused the increase of the three genes 
with levels of overexpression slightly lower than those found when OHSC were previously challenged with $30 \mu \mathrm{M}$ NMDA.

Table 1. Relative expression of genes encoding for the glycolytic enzymes 6-phosphofructo-1-kinase (PFKL), aldolase (ALDOC) and glyceraldehyde-3-phosphate dehydrogenase (GAPDH) in OHSC incubated for different times in presence of increasing concentrations of F-1,6-P2.

\begin{tabular}{ccccc}
\hline Treatment & $\begin{array}{c}\text { Time } \\
\text { (Hours) }\end{array}$ & $\begin{array}{c}\text { PFKL/BD2M } \\
\text { (Fold Increase) }\end{array}$ & $\begin{array}{c}\text { ALDOC/BD2M } \\
\text { (Fold Increase) }\end{array}$ & $\begin{array}{c}\text { GAPDH/BD2M } \\
\text { (Fold Increase) }\end{array}$ \\
\hline \multirow{2}{*}{ Control } & 24 & $1.10 \pm 0.30$ & $1.02 \pm 0.18$ & $1.15 \pm 0.13$ \\
& 48 & $1.07 \pm 0.26$ & $1.15 \pm 0.21$ & $1.07 \pm 0.20$ \\
& 72 & $0.98 \pm 0.21$ & $1.08 \pm 0.23$ & $0.99 \pm 0.14$ \\
\hline \multirow{2}{*}{$\mathbf{0 . 5}$ mM F-1,6-P2 } & 24 & $4.64 \pm 0.62^{\mathrm{a}, \mathrm{b}}$ & $0.94 \pm 0.11$ & $1.14 \pm 0.25$ \\
& 48 & $7.89 \pm 0.88^{\mathrm{a}, \mathrm{b}}$ & $1.09 \pm 0.18$ & $1.09 \pm 0.18$ \\
& 72 & $11.26 \pm 1.23^{\mathrm{a}, \mathrm{b}}$ & $3.67 \pm 0.43^{\mathrm{a}, \mathrm{b}}$ & $8.38 \pm 1.23^{\mathrm{a}, \mathrm{b}}$ \\
\hline \multirow{2}{*}{$\mathbf{1} \mathbf{~ m M ~ F - 1 , 6 - P 2}$} & 24 & $5.16 \pm 0.49^{\mathrm{a}, \mathrm{b}}$ & $1.11 \pm 0.17$ & $1.06 \pm 0.16$ \\
& 48 & $10.54 \pm 1.18^{\mathrm{a}, \mathrm{b}}$ & $0.97 \pm 0.09$ & $0.94 \pm 0.10$ \\
& 72 & $15.92 \pm 1.66^{\mathrm{a}, \mathrm{b}}$ & $4.71 \pm 0.75^{\mathrm{a}, \mathrm{b}}$ & $11.55 \pm 2.03^{\mathrm{a}, \mathrm{b}}$ \\
\hline \multirow{2}{*}{$\mathbf{5}$ mM F-1,6-P2 } & 24 & $9.75 \pm 0.95^{\mathrm{a}, \mathrm{b}}$ & $1.21 \pm 0.26$ & $1.19 \pm 0.21$ \\
& 48 & $14.21 \pm 1.58^{\mathrm{a}, \mathrm{b}}$ & $1.34 \pm 0.31$ & $1.32 \pm 0.18$ \\
& 72 & $21.09 \pm 2.36^{\mathrm{a}, \mathrm{b}}$ & $6.92 \pm 0.95^{\mathrm{a}, \mathrm{b}}$ & $17.46 \pm 2.67^{\mathrm{a}, \mathrm{b}}$ \\
\hline
\end{tabular}

Values are the mean \pm S.D. of 5 experiments from 5 different OHSC preparations and are expressed as fold increase respect to values recorded in control OHSC at corresponding times (see Figure 7 for control values of PFKL and Figure 8 for those of ALDOC and GAPDH). ${ }^{a}$ Significantly different from controls, $p<0.001 .{ }^{b}$ Significantly different from values recorded in OHSC previously challenged with $30 \mu \mathrm{M}$ NMDA and then supplemented with the same F-1,6-P2 concentration, $p<0.01$.

\section{Discussion}

The phenomenon of glutamate-mediated excitotoxicity plays a central role in acute and chronic neurodegenerations and represents a target for new therapeutic approaches in numerous pathological states, including cerebral ischemia, stroke, traumatic brain injury [35-37]. Organotypic hippocampal slice cultures represent a useful in vitro model with which to study not only the effects of excitotoxicity (triggered by the challenge with NMDA) on nervous cell metabolism and functions [38] but also to evaluate efficacy of drug treatments [39].

In the present study, treatment of OHSC with $30 \mu \mathrm{M}$ NMDA for $3 \mathrm{~h}$ at $37^{\circ} \mathrm{C}$ induced long lasting damages to nervous cells progressing during the whole observational time (72 h). Cell death increased by increasing the time of incubation and was accompanied by decrease in ATP concentration. Although part of this effect might be related to decrease in the number of living cells, it is worth underlining that dramatic decrease in the ATP/ADP ratio, which is considered a good indicator of the mitochondrial phosphorylating capacity [40], and remarkable reduction of the ECP, representing a measure of the energy wellness of the cell [41], were recorded. In addition, the derangement of energy metabolism in OHSC after treatment with NMDA was also evidenced by the almost three times and six times increase in AMP and oxypurines, respectively, strongly demonstrating activation of the adenine nucleotide degradation pathway depleting the cellular content of the high-energy phosphate compounds. In this context of sustained dysmetabolism, cerebral cell response was to increase the rate of glycolysis (increase in lactate efflux in the medium, Figure 6) without changing the expression either of the gene encoding for the key regulatory enzyme of glycolysis (PFKL) or of the genes encoding for the immediately following enzymes of the glycolytic pathway (ALDOC and GAPDH) (Figures 7 and 8). This phenomenon, termed as hyperglycolysis, has been shown to occur following TBI [42] and has been associated to the sub-chronic phase following severe (but not mild) TBI [7].

The addition to the incubation medium of F-1,6-P2 following the induction of excitotoxicity had dose-dependent beneficial effects on cerebral cell survival and metabolism. Our results seem to inversely associate reduction of cell mortality with improvement in energy metabolism caused by 
F-1,6-P2. Particularly at the highest concentration tested, F-1,6-P2 restored ATP and GTP concentrations to values detected in control OHSC. ATP rescue was accompanied by high value of the ATP/ADP ratio and ECP, and decreased efflux of lactate in the medium (but still higher than control OHSC), thus indicating no mitochondrial dysfunction and normal cell energy state.

Results of the gene expression analysis clearly showed, for the first time to the best of our knowledge, that the gene encoding for 6-phosphofructo-1-kinase (PFKL) was time and dose-dependently increased by any dose of F-1,6-P2 tested. Additionally, at the longest time of incubation post NMDA challenge, a dose dependent increase in ADLOC and GAPDH was also observed.

These results strongly suggest that F-1,6-P2, notwithstanding is a highly negatively charged molecule at physiological $\mathrm{pH}$, can enter the cell in its intact form where it acts as a neuroprotector against NMDA excitotoxicity. While at physiological concentration the biochemical role of F-1,6-P2 as a substrate of aldolase and a positive allosteric modulator of 6-phosphofructo-1-kinase is well established [43], little is known either about the mechanisms involved in its cellular uptake or about the biochemical processes involved in its beneficial effects under conditions of cell sufferance.

Using the isolated Langendorff-perfused rat heart, we have previously shown that exogenous F-1,6-P2 is actively metabolized by intact cardiomyocytes [44] and taken up through the involvement of the dicarboxylate transporter [45]. Since this transporter has been found in cerebral cells [46,47], it is conceivable hypothesizing that, even under the experimental conditions used in the present study, F-1,6-P2 might cross the nervous cell membranes involving the same transport mechanism.

Although it has not been demonstrated whether F-1,6-P2 is a privileged, advantageous substrate for cell metabolism (its use in alternative to glucose would allow saving two ATP-dependent phosphorylating reactions, leading to a net production of 4 ATP moles/mole of F-1,6-P2 consumed, rather than 2 moles of ATP/mole of glucose consumed through glycolysis), several studies have shown that exogenous F-1,6-P2 at various dosage improves energy metabolism under conditions of cellular energetic crisis [19-25]. These effects, causing the increase in the concentrations of high-energy phosphates and of the cell phosphorylation potential $[19,20,48]$, have been connected, in part, to a decrease in intracellular free calcium ions having positive influence on mitochondrial functions [49].

According to the results of the gene expressions of PFKL, ALDOC and GAPDH it is possible adding to the list of changes of cell metabolism/functions, induced by exogenous F-1,6-P2, this previously unknown and unexpected effect. If the increase in ALDOC and GAPDH can be interpreted as an adaptive mechanism, occurring only after relatively long time of incubation with F-1,6-P2 and after PFKL have remarkably increased, the augmentation of PFKL is certainly a direct consequence of the presence of increasing concentrations of F-1,6-P2 in the OHSC culture medium during the recovery phase, post NMDA challenge. Since these overexpressions were also measured in OHSC incubated for the same times with the same dosages of F-1,6-P2, but without prior challenge with NMDA, it is possible to exclude that uptake of F-1,6-P2 might take place only under conditions of altered cell membrane permeability, as it occurs after NMDA treatment [50].

It can be hypothesized that the overexpressions of the aforementioned genes result in a robust increase of the glycolytic flow. If occurring during mitochondrial dysfunction, higher glycolytic rates may be deleterious for cerebral cells and provoke hyperglycolysis [7,50]. Differently, when taking place with normal mitochondrial functions, higher glycolytic rates lead to improvement of cell energy state [7,51]. Furthermore, various studies underlined the roles of ALDOC and GAPDH in the cross-talk between neurons and astrocytes and in the physiopathological mechanisms regulating cerebral cell energy metabolism [52-57].

Although further studies in laboratory animals are needed, these results corroborate previous observations showing the beneficial effects of F-1,6-P2 on brain metabolism and functions under various stressing conditions [19-26]. The previously unreported effects of this drug on the expressions of genes encoding for key glycolytic enzymes represent a new evidence that exogenous F-1,6-P2 might represent an additional valid substrate for cell energy metabolism, of particular efficacy during period 
of metabolic sufferance characterized by mitochondrial dysfunction. Studies to determine the transport mechanisms involved in the cellular uptake of exogenous F-1,6-P2 are certainly needed.

\section{Materials and Methods}

\subsection{Organotypic Hippocampal Slice Cultures}

The organotypic hippocampal slice cultures (OHSC) were prepared using a method described in detail elsewhere $[34,58]$ and all procedures used were in accordance with UK regulations under the Animals (Scientific Procedures) Act of 1986 and approved by the Ethical Committee of the Catholic University of Rome (number 1F295.52, date 10-20-2017). Briefly, hippocampi from 8 to 10 days old Wistar rats were isolated and sliced at a thickness of $400 \mu \mathrm{m}$, using a Mcllwain tissue chopper (Harvard Apparatus, Edenbridge, UK). The slices were then placed in plate inserts, $0.4 \mathrm{~mm}$ Millicel membrane and $30 \mathrm{~mm}$ diameter, previously treated with a coating solution of $320 \mu \mathrm{g} / \mathrm{mL}$ of poly-D-lysine (Sigma, St. Louis, MO, USA) and $80 \mu \mathrm{g} / \mathrm{mL}$ of laminin (Sigma) in sterile distilled water. The cultures were fed initially in $1200 \mu \mathrm{L}$ NeuroBasal-A medium (Invitrogen, Loughborough, UK), containing B27 supplement (Invitrogen) (1 mL/100 mL medium), $5 \mathrm{mg} / \mathrm{mL}$ glucose (Sigma), $1 \mathrm{mM}$ glutamine (Sigma) and incubated at $37{ }^{\circ} \mathrm{C}$ under humidified atmosphere of $95 \% \mathrm{O}_{2}+5 \% \mathrm{CO}_{2}$. After two days in vitro, the NeuroBasal-A medium was replaced with full serum-containing medium, consisting of $25 \%$ heat-inactivated horse serum, 25\% Hanks'-balanced salt solution, 50\% minimum essential medium (all Invitrogen), $1 \mathrm{mM}$ glutamine (Sigma), and $5 \mathrm{mg} / \mathrm{mL}$ D-glucose (Sigma). After approximately 10 days, when cultures adhered to the membrane and showed clear definition of the neuronal regions CA1, CA3 and dentate gyrus, fresh medium was added to the healthy cultures and the wells were used to perform the experiments.

\subsection{NMDA and F-1,6-P2 Treatments}

Excitotoxic effects of NMDA to OHSC were induced by adding $30 \mu \mathrm{M}$ NMDA to culture medium for $3 \mathrm{~h}$ [59]. This NMDA concentration and timing of NMDA exposure were the best conditions causing significant (but not excessive) cell death and remarkable metabolic changes to OHSC, as evidenced by previous studies [59] and by preliminary experiments in which lower NMDA doses and/or shortest incubation times were tested (data not shown). At the end of this incubation time, the NMDA-containing medium was removed and OHSC were allowed to recover in fresh full serum-containing medium without or with the addition of F-1,6-P2 $(0.5,1$ and $1.5 \mathrm{mM})$. The recovery time at $37^{\circ} \mathrm{C}$ under humidified atmosphere of $95 \%$ air and $5 \% \mathrm{CO}_{2}$ was prolonged for 24,48 or $72 \mathrm{~h}$. At each time point, the medium was collected and stored at $-80{ }^{\circ} \mathrm{C}$ for $\mathrm{LDH}$ and lactate assays, the cultures were washed 3 times with $500 \mu \mathrm{L}$ of ice-cold PBS and then processed to extract RNA for real-time quantitative PCR analysis.

In a different set of experiments, using the same treatment protocol, cultures were washed 3 times with $500 \mu \mathrm{L}$ of ice cold PBS and then immediately deproteinized with $500 \mu \mathrm{L}$ of an ice cold organic solvent mixture $\left(75 \% \mathrm{CH}_{3} \mathrm{CN}+25 \% 10 \mathrm{mM} \mathrm{NaH}_{2} \mathrm{PO}_{4}, \mathrm{pH}\right.$ 7.4). This processing allowed obtaining samples suitable for the subsequent HPLC analysis of low molecular weight metabolites [60].

In a specific set of experiments, dedicated to evaluating the effects on gene expression, OHSC were incubated with F-1,6-P2 $(1.5 \mathrm{mM})$ for 24,48 and $72 \mathrm{~h}$ with no previous challenge with NMDA. Results obtained under the different experimental conditions were compared to OHSC incubated for the same times with neither previous NMDA challenge nor addition of F-1,6-P2.

\subsection{LDH and Lactate Assays}

One hundred $\mu \mathrm{L}$ of each sample of culture medium from the various OHSC were used to determine LDH release as a measure of cell death. The enzyme activity was determined spectrophotometrically (Agilent 89090A, Agilent Technologies, Santa Clara Ca, CA, USA) following the time-dependent 
disappearance of NADH at $340 \mathrm{~nm}$ in a mixture containing $2 \mathrm{mM}$ pyruvate, $200 \mu \mathrm{M}$ NADH and $20 \mathrm{mM}$ Tris-HCl buffer $\mathrm{pH} 7.6$, according to standardized protocol [61].

The spectrophotometric determination of lactate was carried out following the method described by Artiss et al. [62]. Briefly, the reaction mixture contained $100 \mathrm{mM}$ Tris-HCl, $1.5 \mathrm{mM}$ $\mathrm{N}$-ethyl- $\mathrm{N}$-2-hydroxy-3-sulfopropyl-3-methylalanine, $1.7 \mathrm{mM}$ 4-aminoantipirine, $5 \mathrm{IU}$ horseradish peroxidase. One hundred $\mu \mathrm{L}$ of each sample were added to the mixture, let to stand for $5 \mathrm{~min}$ and read at $545 \mathrm{~nm}$ wavelength. The reaction was started with the addition of $5 \mathrm{IU}$ of lactate oxidase to the cuvette (finale volume $=1 \mathrm{~mL}$ ) and it was considered ended when no change in absorbance was recorded for at least $2 \mathrm{~min}$. To calculate lactate, the difference in absorbance at $545 \mathrm{~nm}$ wavelength ( $\Delta$ abs) of each sample was interpolated with a calibration curve obtained by plotting $\Delta$ abs measured in standard solutions of lactate with increasing known concentrations.

\subsection{HPLC Analysis of Metabolites}

The simultaneous separation of high-energy phosphates (ATP, ADP, AMP, GTP), purine nucleosides (inosine, adenosine, guanosine) and oxypurines (hypoxanthine, xanthine, uric acid) in the protein-free cell extracts $(200 \mu \mathrm{L})$ was carried out using previously established ion pairing HPLC methods which utilize tetrabutylammonium hydroxide as the pairing reagent [63]. Separation was obtained using a Hypersil C-18, $250 \times 4.6 \mathrm{~mm}, 5 \mu \mathrm{m}$ particle size column, provided with its own guard column (Thermo Fisher Scientific, Rodano, Milan, Italy). The HPLC apparatus consisted of a SpectraSystem P4000 pump system (ThermoFisher Scientific) and a highly-sensitive UV6000LP diode array detector (ThermoFisher Scientific), equipped with $5 \mathrm{~cm}$ light path flow cell and set up between 200 and $300 \mathrm{~nm}$ wavelength. Assignment and calculations of the compounds of interest in chromatographic runs of cell extracts were performed at $260 \mathrm{~nm}$ wavelength by comparing retention times, absorption spectra, and area of the peaks of chromatographic runs of mixtures containing known concentrations of true ultrapure standard mixtures.

\subsection{RNA Extraction and Real Time PCR Analysis}

Total RNA was extracted from hippocampal slices using RNeasyßMini Kit (QIAGEN, Manchester, UK) according to the instructions of the manufacturer. RNA was dissolved in RNase-free water and concentration and purity were determined with a ND-1000 UV-Vis Spectrophotometer (NanoDrop, ThermoFisher Scientidic, Waltham, MO, USA). RNA extract was reversed transcribed to cDNA by Superscript II Reverse Transcriptase Kit (Invitrogen). From each sample, 1 mg of total RNA, 500 ng of oligo dT primers (Roche Molecular Biochemicals, Burgess Hill, UK), $4 \mu \mathrm{L}$ of First Strand Buffer and $200 \mathrm{U}$ of Superscript II Reverse Transcriptase in a total volume of $20 \mu \mathrm{L}$ were incubated at $42{ }^{\circ} \mathrm{C}$ for $50 \mathrm{~min}$ and $70^{\circ} \mathrm{C}$ for $15 \mathrm{~min}$.

Real Time PCR with melting curve analysis was performed in Bio-Rad iQ5 Real-time PCR Detection System (Bio-Rad, Hercules, CA, USA). In each reaction, $100 \mathrm{ng}$ of cDNA sample was combined with a reaction mixture containing $25 \mu \mathrm{L}$ of $2 \times$ SYBR Green PCR Master Mix (Applied Biosystems, Warrington, $\mathrm{UK}$ ), each primer (at final concentration of $300 \mathrm{nM}$ ), and RNase-free water in a final volume of $50 \mu \mathrm{L}$. The thermal profile began with incubation at $95^{\circ} \mathrm{C}$ for $10 \mathrm{~min}$, followed by 40 cycles of amplification alternating between $94^{\circ} \mathrm{C}$ for $15 \mathrm{~s}$ and $60{ }^{\circ} \mathrm{C}$ for $60 \mathrm{~s}$. After amplification to confirm the specificity of reactions, a melting curve was produced by conducting 81 cycles of $30 \mathrm{~s}$ of melting every $0.5^{\circ} \mathrm{C}$ from 55 to $95^{\circ} \mathrm{C}$. Final data were analyzed by the iQ ${ }^{\mathrm{TM}} 5$ Optical System Software (Bio-Rad). Primers for PFKL (isoform L of 6-phosphofructo-1-kinase, NM_013190.4), ALDOC (aldolase C, NM_012497.1), GAPDH (glyceraldehyde-3-phosphate dehydrogenase, NM_017008.4) were designed with the 0.2 version of the Primer3 Input software developed by the Whitehead Institute for Biomedical Research (Cambridge, MA, USA) and using as template the sequences of Rattus norvegicus. For accurate gene expression measurements with Real Time PCR, results were normalized to a fixed reference, therefore the constitutively expressed housekeeping gene of Rattus norvegicus B2M ( $\beta$-2-microglobulin, NM_017314.1) was selected using the geNorm Housekeeping Gene Selection Kit (Primer Design 
Ltd., Southampton, UK) from a list containing 12 candidate reference genes. Changes in transcript abundance of tested genes were calculated using the $2^{-\Delta \Delta C T}$ method as described by Livak and Schmittgen [64].

\subsection{Statistics}

The within group comparison at each time was performed by the one-way analysis of variance (ANOVA). Differences across groups were estimated by the two-way ANOVA. Fisher's protected least square was used as the post hoc test. Only $p$-values of less than 0.05 were considered as statistically significant.

Author Contributions: Conceptualization, K.M.Y and V.D.P.; methodology, G.L. (Giacomo Lazzarino); software, C.S.; validation, A.M.A., G.C. and M.C.; formal analysis, G.L. (Giacomo Lazzarino), K.M.Y. and A.M.A.; investigation, A.B. and M.C.; data curation, G.C. and K.M.Y.; writing - original draft preparation, G.L. (Giuseppe Lazzarino) and B.T.; writing-review and editing, V.D.P, A.B., G.L. (Giacomo Lazzarino), M.C., C.S. and K.M.Y.; supervision, V.D.P., G.L. (Giuseppe Lazzarino) and B.T.

Funding: This research received no external funding.

Conflicts of Interest: The authors declare no conflict of interest.

\section{References}

1. de Lores Arnaiz, G.R.; Ordieres, M.G. Brain $\mathrm{Na}(+), \mathrm{K}(+)$-ATPase activity in aging and disease. Int. J. Biomed. Sci. 2014, 10, 85-102.

2. Anandhan, A.; Jacome, M.S.; Lei, S.; Hernandez-Franco, P.; Pappa, A.; Panayiotidis, M.I.; Powers, R.; Franco, R. Metabolic dysfunction in Parkinson's disease: Bioenergetics, redox homeostasis and central carbon metabolism. Brain Res. Bull. 2017, 133, 12-30. [CrossRef]

3. Piacentini, R.; Li Puma, D.D.; Mainardi, M.; Lazzarino, G.; Tavazzi, B.; Arancio, O.; Grassi, C. Reduced gliotransmitter release from astrocytes mediates tau-induced synaptic dysfunction in cultured hippocampal neurons. Glia 2017, 65, 1302-1316. [CrossRef] [PubMed]

4. Wang, W.; Zhang, F.; Li, L.; Tang, F.; Siedlak, S.L.; Fujioka, H.; Liu, Y.; Su, B.; Pi, Y.; Wang, X. MFN2 couples glutamate excitotoxicity and mitochondrial dysfunction in motor neurons. J. Biol. Chem. 2015, 290, 168-182. [CrossRef]

5. Kumagai, A.; Sasaki, T.; Matsuoka, K.; Abe, M.; Tabata, T.; Itoh, Y.; Fuchino, H.; Wugangerile, S.; Suga, M.; Yamaguchi, T.; et al. Monitoring of glutamate-induced excitotoxicity by mitochondrial oxygen consumption. Synapse 2018. [CrossRef]

6. Serpa, A.; Pinto, I.; Bernardino, L.; Cascalheira, J.F. Combined neuroprotective action of adenosine A1 and cannabinoid CB1 receptors against NMDA-induced excitotoxicity in the hippocampus. Neurochem. Int. 2015, 87, 106-109. [CrossRef] [PubMed]

7. Amorini, A.M.; Lazzarino, G.; Di Pietro, V.; Signoretti, S.; Lazzarino, G.; Belli, A.; Tavazzi, B. Severity of experimental traumatic brain injury modulates changes in concentrations of cerebral free amino acids. J. Cell. Mol. Med. 2017, 21, 530-542. [CrossRef]

8. Amorini, A.M.; Lazzarino, G.; Di Pietro, V.; Signoretti, S.; Lazzarino, G.; Belli, A.; Tavazzi, B. Metabolic, enzymatic and gene involvement in cerebral glucose dysmetabolism after traumatic brain injury. Biochim. Biophys. Acta 2016, 1862, 679-687. [CrossRef]

9. Fresta, C.G.; Chakraborty, A.; Wijesinghe, M.B.; Amorini, A.M.; Lazzarino, G.; Lazzarino, G.; Tavazzi, B.; Lunte, S.M.; Caraci, F.; Dhar, P.; et al. Non-toxic engineered carbon nanodiamond concentrations induce oxidative/nitrosative stress, imbalance of energy metabolism, and mitochondrial dysfunction in microglial and alveolar basal epithelial cells. Cell Death Dis. 2018, 9, 245. [CrossRef]

10. Gray, J.J.; Zommer, A.E.; Bouchard, R.J.; Duval, N.; Blackstone, C.; Linseman, D.A. N-terminal cleavage of the mitochondrial fusion GTPase OPA1 occurs via a caspase-independent mechanism in cerebellar granule neurons exposed to oxidative or nitrosative stress. Brain Res. 2013, 1494, 28-43. [CrossRef] [PubMed] 
11. Gerbatin, R.D.R.; Cassol, G.; Dobrachinski, F.; Ferreira, A.P.O.; Quines, C.B.; Pace, I.D.D.; Busanello, G.L.; Gutierres, J.M.; Nogueira, C.W.; Oliveira, M.S.; et al. Guanosine protects against traumatic brain injury-induced functional impairments and neuronal loss by modulating excitotoxicity, mitochondrial dysfunction, and inflammation. Mol. Neurobiol. 2017, 54, 7585-7596. [CrossRef]

12. Shalaby, H.N.; El-Tanbouly, D.M.; Zaki, H.F. Topiramate mitigates 3-nitropropionic acid-induced striatal neurotoxicity via modulation of AMPA receptors. Food Chem. Toxicol. 2018, 118, 227-234. [CrossRef]

13. Tai, S.H.; Lee, W.T.; Lee, A.C.; Lin, Y.W.; Hung, H.Y.; Huang, S.Y.; Wu, T.S.; Lee, E.J. Therapeutic window for YC-1 following glutamate-induced neuronal damage and transient focal cerebral ischemia. Mol. Med. Rep. 2018, 17, 6490-6496. [CrossRef]

14. Lao, K.; Ji, N.; Zhang, X.; Qiao, W.; Tang, Z.; Gou, X. Drug development for Alzheimer's disease: Review. J. Drug Target 2018, 20,1-10. [CrossRef]

15. Schumacher, M.; Denier, C.; Oudinet, J.P.; Adams, D.; Guennoun, R. Progesterone neuroprotection: The background of clinical trial failure. J. Steroid Biochem. Mol. Biol. 2016, 160, 53-66. [CrossRef]

16. Oláh, J.; Orosz, F.; Puskás, L.G.; Hackler, L., Jr.; Horányi, M.; Polgár, L.; Hollán, S.; Ovádi, J. Triosephosphate isomerase deficiency: Consequences of an inherited mutation at mRNA, protein and metabolic levels. Biochem. J. 2005, 392 Pt 3, 675-683. [CrossRef]

17. Lazzarino, G.; Cattani, L.; Costrini, R.; Mulieri, L.; Candiani, A.; Galzigna, L. Increase of intraerythrocytic fructose-1,6-diphosphate after incubation of whole human blood with fructose-1,6-diphosphate. Clin. Biochem. 1984, 17, 42-45. [CrossRef]

18. Alva, N.; Alva, R.; Carbonell, T. Fructose 1,6-bisphosphate: A summary of its cytoprotective mechanism. Curr. Med. Chem. 2016, 23, 4396-4417. [CrossRef]

19. Lazzarino, G.; Nuutinen, M.E.; Tavazzi, B.; Cerroni, L.; Di Pierro, D.; Giardina, B. Preserving effect of fructose-1,6-bisphosphate on high-energy phosphate compounds during anoxia and reperfusion in isolated langendorff-perfused rat hearts. J. Mol. Cell. Cardiol. 1991, 23, 13-23. [CrossRef]

20. Tavazzi, B.; Cerroni, L.; Di Pierro, D.; Lazzarino, G.; Nuutinen, M.; Starnes, J.W.; Giardina, B. Oxygen radical injury and loss of high-energy compounds in anoxic and reperfused rat heart: Prevention by exogenous fructose-1,6-bisphosphate. Free Radic. Res. Commun. 1990, 10, 167-176. [CrossRef]

21. Cohen, J.E.; Atluri, P.; Taylor, M.D.; Grand, T.J.; Liao, G.P.; Panlilio, C.M.; Suarez, E.E.; Zentko, S.E.; Hsu, V.M.; Berry, M.F.; et al. Fructose 1,6-diphosphate administration attenuates post-ischemic ventricular dysfunction. Heart Lung Circ. 2006, 15, 119-123. [CrossRef] [PubMed]

22. Romsi, P.; Kaakinen, T.; Kiviluoma, K.; Vainionpää, V.; Hirvonen, J.; Pokela, M.; Ohtonen, P.; Biancari, F.; Nuutinen, M.; Juvonen, T. Fructose-1,6-bisphosphate for improved outcome after hypothermic circulatory arrest in pigs. J. Thorac. Cardiovasc. Surg. 2003, 125, 686-698. [CrossRef] [PubMed]

23. Markov, A.K.; Brumley, M.A.; Figueroa, A.; Skelton, T.N.; Lehan, P.H. Hemodynamic effects of fructose 1,6-diphosphate in patients with normal and impaired left ventricular function. Am. Heart J. 1997, 133, 541-549. [CrossRef]

24. Riedel, B.J.; Gal, J.; Ellis, G.; Marangos, P.J.; Fox, A.W.; Royston, D. Myocardial protection using fructose-1,6-diphosphate during coronary artery bypass graft surgery: A randomized, placebo-controlled clinical trial. Anesth. Analg. 2004, 98, 20-29. [CrossRef]

25. Kaakinen, T.; Naukkarinen, A.; Tuominen, H.; Romsi, P.; Nuutinen, M.; Biancari, F.; Juvonen, T. Neuronal ultrastructure is preserved by fructose-1,6-bisphosphate after hypothermic circulatory arrest in pigs. J. Thorac. Cardiovasc. Surg. 2005, 130, 1475-1476. [CrossRef] [PubMed]

26. Kaakinen, T.; Heikkinen, J.; Dahlbacka, S.; Alaoja, H.; Laurila, P.; Kiviluoma, K.; Salomäki, T.; Romsi, P.; Tuominen, H.; Biancari, F.; et al. Fructose-1,6-bisphosphate supports cerebral energy metabolism in pigs after ischemic brain injury caused by experimental particle embolization. Heart Surg. Forum 2006, 9, E828-E835. [CrossRef] [PubMed]

27. Zhou, J.; Wang, F.; Zhang, J.; Gao, H.; Yang, Y.; Fu, R. Repeated febrile convulsions impair hippocampal neurons and cause synaptic damage in immature rats: Neuroprotective effect of fructose-1,6-diphosphate. Neural Regen. Res. 2014, 9, 937-942. [CrossRef]

28. Catarina, A.V.; Luft, C.; Greggio, S.; Venturin, G.T.; Ferreira, F.; Marques, E.P.; Rodrigues, L.; Wartchow, K.; Leite, M.C.; Gonçalves, C.A.; et al. Fructose-1,6-bisphosphate preserves glucose metabolism integrity and reduces reactive oxygen species in the brain during experimental sepsis. Brain Res. 2018, 1698, 54-61. [CrossRef] 
29. Liu, J.; Hirai, K.; Litt, L. Fructose-1,6-bisphosphate does not preserve ATP in hypoxic-ischemic neonatal cerebrocortical slices. Brain Res. 2008, 1238, 230-238. [CrossRef]

30. Hofer, R.E.; Wagner, S.R., 4th; Pasternak, J.J.; Albrecht, R.F., 2nd; Gallagher, W.J.; Lanier, W.L. Fructose-1,6-bisphosphate and fructose-2,6-bisphosphate do not influence brain carbohydrate or high-energy phosphate metabolism in a rat model of forebrain ischemia. J. Neurosurg. Anesthesiol. 2009, 21, 31-39. [CrossRef]

31. Lossi, L.; Alasia, S.; Salio, C.; Merighi, A. Cell death and proliferation in acute slices and organotypic cultures of mammalian CNS. Prog. Neurobiol. 2009, 88, 221-245. [CrossRef]

32. Alasia, S.; Aimar, P.; Merighi, A.; Lossi, L. Context-dependent toxicity of amyloid- $\beta$ peptides on mouse cerebellar cells. J. Alzheimers Dis. 2012, 30,41-51. [CrossRef]

33. Grabiec, U.; Hohmann, T.; Hammer, N.; Dehghani, F. Organotypic hippocampal slice cultures as a model to study neuroprotection and invasiveness of tumor cells. J. Vis. Exp. 2017. [CrossRef]

34. Di Pietro, V.; Amin, D.; Pernagallo, S.; Lazzarino, G.; Tavazzi, B.; Vagnozzi, R.; Pringle, A.; Belli, A. Transcriptomics of traumatic brain injury: Gene expression and molecular pathways of different grades of insult in a rat organotypic hippocampal culture model. J. Neurotrauma 2010, 27, 349-359. [CrossRef]

35. Krzyżanowska, W.; Pomierny, B.; Bystrowska, B.; Pomierny-Chamioło, L.; Filip, M.; Budziszewska, B.; Pera, J. Ceftriaxone- and $\mathrm{N}$-acetylcysteine-induced brain tolerance to ischemia: Influence on glutamate levels in focal cerebral ischemia. PLoS ONE 2017, 12. [CrossRef]

36. Lai, T.W.; Zhang, S.; Wang, Y.T. Excitotoxicity and stroke: Identifying novel targets for neuroprotection. Prog. Neurobiol. 2014, 115, 157-188. [CrossRef]

37. Lin, C.J.; Chen, T.H.; Yang, L.Y.; Shih, C.M. Resveratrol protects astrocytes against traumatic brain injury through inhibiting apoptotic and autophagic cell death. Cell Death Dis. 2014. [CrossRef]

38. Jang, S.; Kim, H.; Kim, H.J.; Lee, S.K.; Kim, E.W.; Namkoong, K.; Kim, E. Long-term culture of organotypic hippocampal slice from old 3xTg-AD mouse: An ex vivo model of Alzheimer's disease. Psychiatry Investig. 2018, 15, 205-213. [CrossRef]

39. Saliba, S.W.; Marcotegui, A.R.; Fortwängler, E.; Ditrich, J.; Perazzo, J.C.; Muñoz, E.; de Oliveira, A.C.P.; Fiebich, B.L. AM404, paracetamol metabolite, prevents prostaglandin synthesis in activated microglia by inhibiting COX activity. J. Neuroinflamm. 2017, 14, 246. [CrossRef]

40. Maldonado, E.N.; Lemasters, J.J. ATP/ADP ratio, the missed connection between mitochondria and the Warburg effect. Mitochondrion 2014, 19, 78-84. [CrossRef]

41. Lee, J.S.; Wang, R.X.; Alexeev, E.E.; Lanis, J.M.; Battista, K.D.; Glover, L.E.; Colgan, S.P. Hypoxanthine is a checkpoint stress metabolite in colonic epithelial energy modulation and barrier function. J. Biol. Chem. 2018, 293, 6039-6051. [CrossRef] [PubMed]

42. Lama, S.; Auer, R.N.; Tyson, R.; Gallagher, C.N.; Tomanek, B.; Sutherland, G.R. Lactate storm marks cerebral metabolism following brain trauma. J. Biol. Chem. 2014, 289, 20200-20208. [CrossRef]

43. Hill, D.E.; Hammes, G.G. An equilibrium binding study of the interaction of fructose 6-phosphate and fructose-1,6-bisphosphate with rabbit muscle phosphofructokinase. Biochemistry 1975, 14, 203-213. [CrossRef]

44. Tavazzi, B.; Starnes, J.W.; Lazzarino, G.; Di Pierro, D.; Nuutinen, E.M.; Giardina, B. Exogenous fructose-1,6-bisphosphate is a metabolizable substrate for the isolated normoxic rat heart. Basic Res. Cardiol. 1992, 87, 280-289. [CrossRef] [PubMed]

45. Hardin, C.D.; Lazzarino, G.; Tavazzi, B.; Di Pierro, D.; Roberts, T.M.; Giardina, B.; Rovetto, M.J. Myocardial metabolism of exogenous FDP is consistent with transport by a dicarboxylate transporter. Am. J. Physiol. Heart Circ. Physiol. 2001, 281, H2654-H2660. [CrossRef] [PubMed]

46. Pajor, A.M.; Gangula, R.; Yao, X. Cloning and functional characterization of a high-affinity $\mathrm{Na}(+) /$ dicarboxylate cotransporter from mouse brain. Am. J. Physiol. Cell Physiol. 2001, 280, C1215-C1223. [CrossRef] [PubMed]

47. Yodoya, E.; Wada, M.; Shimada, A.; Katsukawa, H.; Okada, N.; Yamamoto, A.; Ganapathy, V.; Fujita, T. Functional and molecular identification of sodium-coupled dicarboxylate transporters in rat primary cultured cerebrocortical astrocytes and neurons. J. Neurochem. 2006, 97, 162-173. [CrossRef]

48. Nuutinen, E.M.; Lazzarino, G.; Giardina, B.; Hassinen, i.e., Effect of exogenous fructose-1,6-bisphosphate on glycolysis in the isolated perfused rat heart. Am. Heart J. 1991, 122, 523-527. [CrossRef]

49. Hassinen, I.E.; Nuutinen, E.M.; Ito, K.; Nioka, S.; Lazzarino, G.; Giardina, B.; Chance, B. Mechanism of the effect of exogenous fructose 1,6-bisphosphate on myocardial energy metabolism. Circulation 1991, 83, 584-593. [CrossRef] [PubMed] 
50. Gao, S.; Yu, Y.; Ma, Z.Y.; Sun, H.; Zhang, Y.L.; Wang, X.T.; Wang, C.; Fan, W.M.; Zheng, Q.Y.; Ma, C.L. NMDAR-Mediated hippocampal neuronal death is exacerbated by activities of ASIC1a. Neurotox. Res. 2015, 28, 122-137. [CrossRef]

51. Di Pietro, V.; Lazzarino, G.; Amorini, A.M.; Signoretti, S.; Hill, L.J.; Porto, E.; Tavazzi, B.; Lazzarino, G.; Belli, A. Fusion or fission: The destiny of mitochondria in traumatic brain injury of different severities. Sci. Rep. 2017, 7, 9189. [CrossRef]

52. Sandoval, M.; Luarte, A.; Herrera-Molina, R.; Varas-Godoy, M.; Santibáñez, M.; Rubio, F.J.; Smit, A.B.; Gundelfinger, E.D.; Li, K.W.; Smalla, K.H.; et al. The glycolytic enzyme aldolase C is up-regulated in rat forebrain microsomes and in the cerebrospinal fluid after repetitive fluoxetine treatment. Brain Res. 2013, 1520, 1-14. [CrossRef]

53. Mamczur, P.; Borsuk, B.; Paszko, J.; Sas, Z.; Mozrzymas, J.; Wiśniewski, J.R.; Gizak, A.; Rakus, D. Astrocyte-neuron crosstalk regulates the expression and subcellular localization of carbohydrate metabolism enzymes. Glia 2015, 63, 328-340. [CrossRef]

54. Tsutsumi, S.; Yamazaki, M.; Miyazaki, T.; Watanabe, M.; Sakimura, K.; Kano, M.; Kitamura, K. Structure-function relationships between aldolase C/zebrin II expression and complex spike synchrony in the cerebellum. J. Neurosci. 2015, 35, 843-852. [CrossRef]

55. Schousboe, A.; Sickmann, H.M.; Bak, L.K.; Schousboe, I.; Jajo, F.S.; Faek, S.A.; Waagepetersen, H.S. Neuron-glia interactions in glutamatergic neurotransmission: Roles of oxidative and glycolytic adenosine triphosphate as energy source. J. Neurosci. Res. 2011, 89, 1926-1934. [CrossRef]

56. Lazarev, V.F.; Dutysheva, E.A.; Komarova, E.Y.; Mikhaylova, E.R.; Guzhova, I.V.; Margulis, B.A. GAPDH-targeted therapy-A new approach for secondary damage after traumatic brain injury on rats. Biochem. Biophys. Res. Commun. 2018, 501, 1003-1008. [CrossRef]

57. Sen, T.; Saha, P.; Sen, N. Nitrosylation of GAPDH augments pathological tau acetylation upon exposure to amyloid-ß. Sci. Signal. 2018, 11. [CrossRef]

58. Di Pietro, V.; Amorini, A.M.; Lazzarino, G.; Yakoub, K.M.; D’Urso, S.; Lazzarino, G.; Belli, A. S100B and glial fibrillary acidic protein as indexes to monitor damage severity in an in vitro model of traumatic brain injury. Neurochem. Res. 2015, 40, 991-999. [CrossRef]

59. Ikegaya, Y.; Kim, J.A.; Baba, M.; Iwatsubo, T.; Nishiyama, N.; Matsuki, N. Rapid and reversible changes in dendrite morphology and synaptic efficacy following NMDA receptor activation: Implication for a cellular defense against excitotoxicity. J. Cell Sci. 2001, 114, 4083-4093.

60. Lazzarino, G.; Amorini, A.M.; Petzold, A.; Gasperini, C.; Ruggieri, S.; Quartuccio, M.E.; Lazzarino, G.; Di Stasio, E.; Tavazzi, B. Serum compounds of energy metabolism impairment are related to disability, disease course and neuroimaging in multiple sclerosis. Mol. Neurobiol. 2017, 54, 7520-7533. [CrossRef]

61. Bergmeyer, H.U. Methods of Enzymatic Analysis, 2nd ed.; Academic Press: New York, NY, USA, 1974; Volume 1-2.

62. Artiss, J.D.; Karcher, R.E.; Cavanagh, K.T.; Collins, S.L.; Peterson, V.J.; Varma, S.; Zak, B. A liquid-stable reagent for lactic acid levels. Application to the Hitachi 911 and Beckman CX7. Am. J. Clin. Pathol. 2000, 114, 139-143. [CrossRef] [PubMed]

63. Bracko, O.; Di Pietro, V.; Lazzarino, G.; Amorini, A.M.; Tavazzi, B.; Artmann, J.; Wong, E.C.; Buxton, R.B.; Weller, M.; Luft, A.R.; et al. 3-Nitropropionic acid-induced ischemia tolerance in the rat brain is mediated by reduced metabolic activity and cerebral blood flow. J. Cereb. Blood Flow Metab. 2014, 34, 1522-1530. [CrossRef] [PubMed]

64. Livak, K.J.; Schmittgen, T.D. Analysis of relative gene expression data using real-time quantitative PCR and the 2(-Delta Delta C(T)) method. Methods 2001, 25, 402-408. [CrossRef] [PubMed]

(C) 2019 by the authors. Licensee MDPI, Basel, Switzerland. This article is an open access article distributed under the terms and conditions of the Creative Commons Attribution (CC BY) license (http://creativecommons.org/licenses/by/4.0/). 